\title{
Public Attitude and Awareness towards Tetanus and Its Vaccine in Riyadh
}

\author{
Mohammed Khalid Azzahrani ${ }^{1}$, Abdulrahman Maneaallah Alsaedy ${ }^{2}$, Amro Attaf Alsalmi, \\ Majed Ali Alshehri ${ }^{4}$, Mishaal Ramzi Alrashoud ${ }^{5}$, Ahmed Khalaf Alanazi ${ }^{6}$, Zakariya Khalid Azzahrani ${ }^{7}$ \\ ${ }^{1,3,4,5,6,7}$ College of medicine, King Saud bin Abdulaziz for Health Sciences, Riyadh, Saudi Arabia \\ ${ }^{2}$ Department of infectious diseases, King Abdulaziz Medical City, Riyadh, Saudi Arabia
}

\begin{abstract}
Objectives: The objectives of this study were to assess the awareness of the public about tetanus and its relation to the demographic characteristics, the awareness about tetanus vaccine, and to identify the deficient aspects of knowledge in regards to tetanus in Riyadh, Saudi Arabia. Background: Tetanus is one of the life threatening, yet easily preventable diseases as it causes for the affected patient involuntary muscle spasms which might lead to death. With the introduction of tetanus vaccine, the prevalence rate was decreased, but still present, thanks to the vaccine. In this study, we aimed to assess the awareness of the public about tetanus and its vaccine in Riyadh, Saudi Arabia. Method: A cross-sectional, survey-based study was conducted in different public places in Riyadh using a validated and a reliable questionnaire, with a calculated sample size of 377 people. They were surveyed about their demographics and their knowledge of tetanus and its vaccine. Statistical Package for the Social Sciences (SPSS) was used to analyze the results and to report them as frequencies and proportions. Results: Of the 377 Participants, $69.2 \%$ of the sample size never heard of tetanus disease. Only $24.2 \%$ of females heard of tetanus compared to $34 \%$ of the male respondents who heard of it. Older people showed greater knowledge with $60 \%$ of people $>55$ years old knew about tetanus, and the minority of young adults (15.8\%) knew about it. Also, people with better income heard of tetanus more than those with less income e.g. $43.8 \%$ of people with an income of $>20000 \mathrm{SAR} k n e w$ about tetanus and only $23.3 \%$ of people with an income of $<5000$ SAR heard of it. Furthermore, as the level of education increases the knowledge increases, but, surprisingly, $60 \%$ of people who had an education below the high school level heard of tetanus. $69 \%$ of the respondents didn't know about tetanus booster vaccine, however, $14.9 \%$ of the participants reported that they took the vaccination. Conclusion: The awareness of tetanus in Riyadh is generally poor despite the good education and health systems. That warrants more attention to the need of more campaigns which educate about tetanus and its prevention. Although a great number of people have taken the booster vaccine, more investigations are needed to analyze the reasons of the vaccination which might be actually due to the exposure to wounds and other risk factors.
\end{abstract}

Keywords: Tetanus, Public Awareness, Riyadh, Vaccine, public attitude

\section{Background}

The infamous tetanus, that is known since ancient times, is not completely eradicated and still can affect different age groups despite the effective immunization programs that have been implemented all over the world. Although nowadays it's a disease of developing countries, it's still seen in developed ones ${ }^{1-2}$ Tetanus is caused by the toxinproducing and spore-forming Clostridium tetani that are ubiquitous in the environments. It is found in the soil, dirt, and feces, and its spores are stable in the environment and it has the capability to cause the disease indefinitely. Therefore, it is difficult to eradicate tetanus despite having an effective vaccine. It enters the body through contaminated skin wounds either by penetrating objects or damaged skin exposed to the dirty environment. ${ }^{3}$

The clinical types of tetanus are classified to generalized, localized, cephalic and neonatal. The former is the most common form. ${ }^{4}$ The disease is characterized by painful muscular contractions, especially the jaw muscles causing "lockjaw". Other classical presentations that develop late in the course of the disease are the abnormal arched back"opisthotonus" and the sardonic smile"risussardonicus". It can also lead to death, most commonly due to respiratory failure. ${ }^{2}$ The disease incidence has declined in developed countries that have implemented the immunizations e.g. 233 cases only have been documented during 2001-2008 in the United States. Puncture wound is the most common risk factor for tetanus but any open wound could be at risk of contamination and infection with tetanus toxins in nonvaccinated individuals particularly if there was no proper wound care. Possible host risk factors for tetanus are diabetes and Intravenous (IV) drug use as reported by the CDC. ${ }^{5}$ During 2001-2008, 15\% of reported cases were in IV drug users. Diabetes accounted for $13 \%$ of cases during 1987-2008 in USA. According to World Health Organization (WHO), neonatal tetanus (a form of tetanus that affects newborns due to lack of the mother's immunization and unsterile delivery practices) was responsible for 180,000 deaths globally in 2002. ${ }^{5-6}$ Kingdom of Saudi Arabia (KSA) is one of the many countries that introduced the vaccination program, and tetanus immunization is part of Expanded Programme on Immunization (EPI) since the1980 s. ${ }^{7}$ According to Ministry of health $(\mathrm{MOH})$ in KSA, the incidence of neonatal tetanus is 0.004 per 1000 live births in 2014, and the immunization coverage among infants is $98.1 \%$. In 2014 , The total number of tetanus (other than neonatal) reported cases in KSA is 11 cases, 10 of which were in Jeddah city. Surprisingly, 6 of those cases occurred in people aged 15-44, and the remaining 5 cases occurred in the age of 45 and above. However, only 1 Saudi is affected that year and there were no reported neonatal cases. ${ }^{8}$

In a study done in King Abdul-Aziz Hospital and Oncology Center from January 2000 through to December 2002, 11 adult cases were diagnosed with tetanus, 4 of them were 


\section{International Journal of Science and Research (IJSR) \\ ISSN (Online): 2319-7064}

Index Copernicus Value (2015): 78.96 | Impact Factor (2015): 6.391

Saudis. Also, the study reported that their immunization status with tetanus toxoid are not updated. ${ }^{7}$ Nevertheless, there is still the possibility of underreported cases due to the fact that the diagnosis is clinical.

Tetanus can affect older people who weren't vaccinated or who were inadequately vaccinated. Nevertheless, a 10-year booster dose is also required to boost the immunity for previously immunized people or the disease can occur. Although the need of boosters is questioned and that primary doses of vaccine are thought to be enough, boosters are recommended by centers like CDC. Also, it's important to mention that there is a variable response and a variable circulating antibodies to the primary immunization series, and in some people the immunity may reach 20-30 years, but boosters are needed to minimize the risk and enhance protection in greater numbers of the population. ${ }^{9-11}$

Health knowledge is an important element of human's life, and knowing how to fight diseases, especially preventable diseases, is one way to survive. Also, knowing the effective strategies that were developed against such diseases should be taught to school's children and the public to increase knowledge and promote health. This research aims to assess the current knowledge and awareness about tetanus and its booster vaccine in people who live in Riyadh- KSA

\section{Materials and Methods}

\section{Study design and setting}

A cross-sectional, survey-based study was conducted in Riyadh, Saudi Arabia. The questionnaire was disseminated in different public places e.g. malls, walking tracks, and parks, and the places were chosen with different cardinal directions (north, east, etc.) to cover different socioeconomic groups. Riyadh is the capital of Saudi Arabia and it has the second largest population after Makkah Al-Mokarramah, but it is the largest in terms of Saudi population. The latest statistical data shows that Riyadh has a population of 8 million, 4.5 million being Saudis. ${ }^{12}$

\section{Sample size and Sampling Technique:}

Raosoft sample size online calculator was used to determine the sample size. The recommended sample size was 377 with $5 \%$ margin of error and a confidence level of $95 \% .{ }^{13} \mathrm{~A}$ convenience sampling was done for those who were available at the different public places in 2016 .

\section{Data Collection methods and instruments:}

A validated questionnaire was taken from a published article, then it was translated by experts from English to Arabic and vice versa and a final Arabic version was formed. ${ }^{3}$ Then, the questionnaire was modified to meet the objectives of this study and to be related to Saudi population. Two questions were added to ask about the tetanus booster vaccine to assess the prevalence of the vaccination. The modified questionnaire was then assessed for the reliability by pilot testing of a sample of 20 who are not included in the primary study. Cronbach's alpha test was done using Statistical Package for the Social Sciences (SPSS) version 22 for the questionnaire's questions without the section of demographics to assess the reliability of tetanus-related questions, and the reliability coefficient was found to be 0.791 which indicates a good internal consistency. The studied variables included about tetanus are: the general knowledge and definition, the cause and transmission, and the vaccine knowledge and prevalence. Furthermore, the general knowledge was tested for its relation to the demographic data. The questionnaire was disseminated in different places by the six co-investigators of the research. They were disseminated in the period between October and December, 2016. Non-Saudis were excluded from the research and only Saudis were included to try to indirectly assess the public health in regards to tetanus in Saudi Arabia. All Saudis, males or females, were included, and various age groups were also included but young children were avoided.

\section{Data management and analysis:}

The participants were coded as serial numbers in Excel 2016. Then, the data was cleaned i.e. improper sheets (empty papers, incomplete answers, or multiple answers) were removed, and 377 sheets were collected in the end. All variables were categorical and even age and income were categorized. Statistical Package for Social Sciences (SPSS) version 22 was used to analyze the data. The variables were entered in SPSS and the frequencies and proportions were done as numerical measures to report the results. Tables of frequencies and counts were generated by SPSS too, and a $2 \times 2$ cross tabulation was generated for the general knowledge in association to the demographic characteristics.

\section{Ethical consideration:}

King Abdullah International Medical Research Center (KAIMRC) reviewed and approved the research. A consent form that has the title and the purpose of the study was attached as the first page in the questionnaire, and only those who voluntarily agree to participate will be included in the research.

\section{Results}

\section{Demographic Characteristics:}

$253(67.1 \%$ of the total sample size) males and $124(32.9 \%)$ females were included in this study. $8(2.1 \%)$ of the participants were $<18$ years old, $48.5 \%$ (183) were $18-24$ years old, 38.7\% (146) were 25-39 years old, 9.3\% (35) were $40-55$, and $1.3 \%$ (5) were $>55$ years old. $42.2 \%$ (159) of the respondents had an income of less than 5000 Saudi ArabianRiyals (SAR), 28.9\% (109) of them had an income within the range of 5000-10000 SAR, 20.4\% (77) had an income between $10000-20000 \mathrm{SAR}$, and $8.5 \%$ (32) of them had an income of more than 20000 SAR.

The educational level of the participants was asked for and it showed the following: none of them had had any education, $1.3 \%$ (5) had only studied the elementary or intermediate schools, 32.1\% (121) had completed high school, 9.8\% (37) had diploma degree, $51.7 \%$ (195) had Bachelor degree, $4.5 \%$ (17) had reached the master degree, and only $0.5 \%$ (2) had PhD. Table 1 shows the baseline demographic characteristics of the participants.

\section{Prevalence:}

In relation to this study's sample size, $69.2 \%$ (261 out of 377 ) of the respondents have never heard of tetanus as a

\section{Volume 6 Issue 1, January 2017 www.ijsr.net}




\section{International Journal of Science and Research (IJSR) \\ ISSN (Online): 2319-7064}

Index Copernicus Value (2015): 78.96 | Impact Factor (2015): 6.391

disease entity. Furthermore, the association of the knowledge to the baseline demographic characteristics were investigated and it's summarized in Table 2. Among males who responded to the survey, 34\% (86) had heard of the disease, while $66 \%$ (167) never had heard of it. In comparison, $24.2 \%$ (30) of females had known the disease, while $75.8 \%$ (94) never heard of the disease. The percentages of those who weren't aware about tetanus in relation to the age are: $62.5 \%$ (5) for people who are $<18$, $84.2 \%$ (154) for people who are 18-24, 59.6\% (87) for those who are $25-39,37.1 \%$ (13) for those who are 40-55, and $40 \%(2)$ for the participants who are $>55$ years old. Also, $76.7 \%$ (122) of those who had an income of $<5000$ Saudi Arabia riyals (SAR) reported that they never heard about tetanus, $71.6 \%$ (78) of the people who had an income of 5000-10000 SAR never heard of tetanus, 55.8\% (43) for those who had an income between 10000-20000 SAR reported that they never heard of it, and $56.2 \%$ (18) for the those who have $>20000$ SAR reported that they never heard of the disease. $40 \%$ ( 2 out the 377 ) of people who had only finished elementary or intermediate schools, $81 \%$ (98) of those who had finished high school reported that they never heard about tetanus, $73 \%$ (27) of people with diploma had never heard of tetanus, $64.6 \%$ (126) of those with bachelor never heard of tetanus, and $47.1 \%$ (8) of people with master degree reported that they never heard about tetanus, and all the people who had $\mathrm{PhD}$ ( 2 out the 377 ) reported that they heard of tetanus.

$72.7 \%$ (274) of the total respondents answered with - Hon't know" to the fact that tetanus is an infection caused by contaminated wounds, while 5.8\% (22) answered with - no", and $21.5 \%$ (81) answered correctly with — $\$$ s".77.7\% (293) of the total respondents didn't have the knowledge about the source of the disease i.e. the microbe that is found in the surrounding environment and soil, and 4\% (15) incorrectly chose - a" as the answer. Regarding the clinical presentation of involuntary muscle spasms and tockjaw", $82.5 \%$ (311) of people chose -Idon't know", 7.4\%(28) chose - a", while 10.1\% (38) chose correctly — $\$$ s". People were asked if the disease could be transmitted from person to person, and the results were $71.4 \%$ (269) didn't know, 15.1 (57) said it is false, and only $13.5 \%$ (51) said it is true. $69 \%$ (260) of respondents reported that they don't know about the booster vaccine for tetanus.85.1\%(321) hadn't received the booster vaccine in the past, while $14.9 \%$ (56) had received it. People were asked if tetanus can develop in people who are not immunized or in people who didn't boost their immunity with the vaccine, and $83.6 \%$ (315) didn't know about the importance of the vaccine, $10.1 \%$ (38) answered wrongly with $-\mathbf{a}$ " to the statement, and only $6.4 \%$

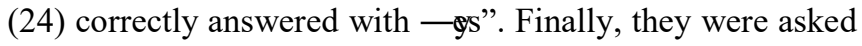
if inadequate immunity with booster vaccines every 10 years and failed immunization in the presence of an open wound that it would results to tetanus, and 74,5\% (281) answered with I don't know", 4.8\% (18) answered that it's not correct, and $20.7 \%$ (78) answered the correct answer with $-\mathrm{s} "$.

\section{Discussion}

This study was done to analyze the knowledge and awareness of tetanus and its vaccine in the public of Saudi
Arabia. The importance of this study is to know if there is a need to promote health in regards to tetanus disease or infectious diseases in general, because very much was done to fight and eradicate the disease especially where it's endemic, and it is important to assess how good is the public health and health knowledge in our community. In this study, the majority of respondents $69.2 \%$ (261 out of 377) had never heard of tetanus. In comparison to a study that was done in Pakistan, the majority of them had known or heard of tetanus $(n=973$; more than $80 \%){ }^{14}$ The discrepancy between our study and their study could be related to the lack of public awareness in the media, schools and public campaigns in our community. It could also be due to the high occurrence of minor injuries in Pakistan which was reported in the study. However, another study that was done in Thailand shows similar number to ours with $68.9 \%$ of their respondents had never known about tetanus disease. ${ }^{15}$ In regards to gender variation in knowledge, males in this study have known tetanus more than females with a percentage of $34 \%$ and $24.2 \%$ respectively. In comparison, an Indian study done in Delhi demonstrated more knowledge about the disease among female groups. ${ }^{16}$ Many reasons can increase the knowledge in a particular population, one of which is the exposure to or the previous infection with tetanus, and males are more prone to be exposed to tetanus since they are more involved in sports, farming, and other activities.

Anyhow, it warrants more attention to female groups in our community regarding health education and awareness, and with educating females, neonatal tetanus can be totally eliminated from the community.

The results also show that the knowledge somehow is related to the age. $60 \%$ of people $>55$ years old knew about tetanus, on the other hand, only $16 \%$ of young adults (18-24 years old) knew about it. The age group of people between 40-55 years old showed the highest percentage of knowledge compared to the others age groups with $63 \%$ of them were knowledgeable.

This means that the awareness is lower in young people in our population. These results are the opposite of a study done in China which showed that the awareness decreases with older age groups. ${ }^{17}$ These results indicate that there may be poor educational programs regarding this issue in the schools, media and public campaigns, and that the knowledge might be more in people who were infected with tetanus since tetanus was more prevalent in the past. The numbers clearly show that there is a problem in the health education in regards to tetanus which may reflect also the deficiency in some public health matters like vaccination and prevention.

When mentioning the level of education of the study participants, we found that when the level of education increases the awareness increases as well. The percentage of people not aware of the disease were $81 \%$ of people with high school degree, $73 \%$ of people with diploma, $64.6 \%$ of those with bachelor, $47.1 \%$ of people with master degree. On the other hand, all the people who had $\mathrm{PhD}(2$ out the 377 ) reported that they heard of tetanus. However, $40 \%$ of people who went only to intermediate or elementary schools 


\section{International Journal of Science and Research (IJSR) \\ ISSN (Online): 2319-7064}

Index Copernicus Value (2015): 78.96 | Impact Factor (2015): 6.391

reported that they hadn't known about tetanus. Generally, the level of education is strongly associated with the level of awareness. This was similar to the results of a study done in China that studied the public awareness about three infectious diseases (TB,HIV, and HBV) $\cdot{ }^{17}$ Although the study was about different infectious diseases, the results were similar and showed that people with higher educational level were more aware of the disease. In a study done in Thailand low socioeconomic status was associated with less awareness of the disease which is similar to our study. ${ }^{15}$ Our study showed that when the income increases the awareness increases significantly. For example, $76.7 \%$ of those who had an income of $<5000$ Saudi Arabian riyals (SAR) reported that they never heard of tetanus. While $55 \%$ and $56 \%$ for those who had an income between 10000-20000 and $>20000$ respectively reported that they never heard of it. This can tell us that the low socioeconomic status is mostly accompanied by less level of education which could explain this finding. It is expected to have a better knowledge and a better health in people with good socioeconomic status. Further investigations of the knowledge aspects were done to determine what the most deficient partsare in order to know which information is lacking in the community. People were asked if tetanus is caused by contaminated wounds and if it is acquired from the environment and from soil and animal feces, $21.5 \%$ and $18.3 \%$ correctly recognized the answer respectively. They were also asked about the clinical presentation which is the muscle spasms and with the classical name tockjaw" given to them and only $10.1 \%$ of them identified it. Furthermore, $15.1 \%$ of the participants thought that the disease could be transmitted from one person to another, $71.4 \%$ didn't know how tetanus is transmitted, and only the minority $(13.5 \%)$ was able to know the mode of transmission. Although $30.8 \%$ of them claimed they know tetanus, the majority of them didn't correctly answer every statement about tetanus, and the most deficient aspect was the clinical presentation. It is also important to mention that people mistakenly thought that tetanus can be transmitted between people, and it was the most statement that people answered incorrectly to.

The third section in the survey analyzed the public knowledge and attitude to tetanus booster vaccine. The majority of the respondents $(69 \%)$ didn't know about the booster vaccine, and $14.9 \%$ of people reported that they took the booster vaccine in our population. In 2007, one American study reported that only $3.6 \%$ of adults have received the vaccine, and approximately $19 \%$ of those who weren't vaccinated had known about the existence of the vaccine. ${ }^{18}$ There is more people in our population that took the vaccination compared to the American population, but we think it's either the time difference between the two studies that made such a discrepancy, or it might be really an indication that our vaccination coverage is good if not better. In comparison, $18.6 \%$ of the respondents had known about tetanus vaccine in a Canadian study. ${ }^{19}$

Another Canadian study showed that $64 \%$ of adults remembered that they had taken the tetanus vaccine, however, only $45 \%$ of them received the vaccine in the past ten years. In that study, the main reason for the last tetanus immunization was due to the risk of exposure as in injuries, and only few of them took it because of a physician's recommendation. ${ }^{20} \mathrm{We}$ think more investigations are needed to be done to analyze the reasons for the vaccinations, because as seen in the Canadian population, the one major reason for tetanus vaccination was due to the exposure to the risk factors e.g. injuries. Although, it's not clear if people know the idea of booster vaccination" and it's possible that they misunderstood it with the primary vaccinations the children required to take. Moreover, the participants were asked if someone could develop tetanus if they haven't been vaccinated against tetanus and $83.6 \%$ of them didn't know the answer and $10.1 \%$ of them disagreed with the statement. Many people couldn't appreciate the need of the vaccination which was also seen in Thailand where $88.2 \%$ of people didn't know its importance. ${ }^{15}$ The lack of knowledge of the importance of the booster vaccine to strengthen the immunity against tetanus may be the reason of the vaccine hesitancy. In addition, $20.8 \%$ of the respondents were knowledgeable and knew that tetanus may develop if there was an inadequate immunity with the presence of open wounds. This may be related to the fact that $21.5 \%$ of the respondents accurately knew that tetanus is caused by wounds contamination. It is important for people to know the risk factors in order to accurately identify the postexposure steps that are needed to be taken, and campaigns that target both increasing awareness of the primary prevention using the vaccine and the post-exposure management could be helpful to entirely eradicate the disease. Nevertheless, primary prevention by the booster vaccine is much safer for the people to avoid the infection, and achieving a better vaccine coverage not only for tetanus but also for the rest of the diseases that can be prevented by vaccines is not impossible.

\section{Conclusion and Recommendations}

As per the results, male gender, older age, people with higher monthly income, and people with higher educational level were indicators for more knowledge about the term "tetanus". Moreover, these indicators were associated with more knowledge about the disease manifestations, potential sources, and the presence of booster vaccines. However, most of the population didn't know basic facts about the disease transmission, how it manifests, and even were not aware of the booster vaccine. Therefore, we recommend awareness campaigns to be performed targeting specific populations, including schools, public hospitals, and lowincome living districts. Moreover, we recommend the utilization of social media to cover larger population with measures like articles, infographic videos, and celebrities' support. In addition, we recommend further studies to specific age groups, socioeconomic status, and different cities to estimate the real prevalence of community awareness of the disease, the potential causes, the manifestation of the disease, and how to prevent it. Also, the history of previous vaccination is needed to be further investigated to know the cause and if there was really a need for the vaccine.

\section{References}

[1] Pearce JM. Notes on tetanus (lockjaw). J NeurolNeurosurgPsychiatry1996;60:332 10.1136/jnnp.60.3.332.

Volume 6 Issue 1, January 2017 


\section{International Journal of Science and Research (IJSR) \\ ISSN (Online): 2319-7064}

Index Copernicus Value (2015): 78.96 | Impact Factor (2015): 6.391

[2] Rhee P, Nunley MK, Demetriades D, Velmahos G, DoucetJJ. Tetanus and trauma: a review and recommendations. J Trauma 2005;58(5):1082-8.

[3] Orimadegun AE, Adepoju AA, AkinyinkaOO. Adolescent girls' understanding of tetanus infection and prevention: implications for the disease control in Western Nigeria. Front Public Health 2014; 2:24. Doi: 10.3389/fpubh.2014.00024.

[4] Pavani Reddy, Thomas P. Bleck, Clostridium tetani (Tetanus) 244, Bleck, Mandell, Douglas, \& Bennett's Principles and Practice of Infectious Diseases, 7th ed Textbook of Critical Care, 7th Edition, 2011 - Churchill Livingstone, An Imprint of Elsevier

[5] CDC. Tetanus surveillance - United States, 20012009. MMWR2011;60:365-96.

[6] World Health Organization. Validation of neonatal tetanus elimination in Andhra Pradesh, India. WklyEpidemiol Rec 2004;79:292-7.

[7] Lubbad EH, Khazindar AM, Ayyub M. Tetanus experience in a public hospital in Western Saudi Arabia. Saudi Med J 2003;24(12):1325-8.

[8] Ministry of Health. Health Statistical Annual Book 1435 (2014). [Updated 2015; Accessed 2016 April 25] Available from URL: http://www.moh.gov.sa/en/Ministry/Statistics/book/Doc uments/Statistical-Book-for-the-Year-1435.pdf

[9] Choi JH, Choo EJ, Huh A, Choi SM, EomJS, Lee JS, et al. Immunogenicity and safety of diphtheria-tetanus vaccine in adults. J Korean MedSci 2010; 25(12):172732. doi: $10.3346 / \mathrm{jkms} .2010 .25 .12 .1727$.

[10]CDC. General recommendations on immunizationrecommendations of the Advisory Committee on Immunization Practices (ACIP). MMWRRecomm Rep 2011;60(No. RR-2):1-64.

[11] Borrow R, Blamer P, Roper MH. The Immunological Basis for Immunization Series Module 3: Tetanus Update 2006. Geneva, World HealthOrganization; 2006. [Accessed 2016 April 25] Available from URL: http://apps.who.int/iris/bitstream/10665/43687/1/97892 41595551_eng.pdf

[12] General Authority for Statistics. Demographic Research Bulletin (2016). [Updated 2016 November 15; Accessed 2016 December 10] Available from URL: http://www.stats.gov.sa/en/4522

[13] RaoSoft. Sample size calculator. [ Accessed 2016 August 8] Available from URL: http://www.raosoft.com/samplesize.html

[14] Wasay M, Malik A, Fahim A, Yousuf A, Chawla R, Daniel H, et al. Knowledge and attitudes about tetanus and rabies: a population-based survey from Karachi, Pakistan. J Pak Med Assoc2012 ;Apr;62(4):378-82.

[15] Pandejpong D, Pisalprapa P. Awareness of and factors influencing willingness to receive a tetanus-diphtheria toxoid booster vaccine among Thai adults. Southeast Asian J Trop Med Public Health 2013;44(6):1047-54.

[16] Taneja DK, Kumar R, Dabas P, Ingle GK. Knowledge regarding tetanus toxoid immunization among persons attending health mela in Delhi. J Commun Dis 2003 Dec;35(4):256-62.

[17] Liu H, Li M, Jin M, Jing F, Wang H, Chen K. Public awareness of three major infectious diseases in rural Zhejiang province, China: a cross-sectional study. BMC
Infect Dis 2013 Apr 29;13:192.doi: 10.1186/1471-233413-192.

[18] Miller BL, Kretsinger K, Euler GL, Lu PJ, Ahmed F. Barriers to early uptake of tetanus, diphtheria and acellular pertussis vaccine (Tdap) among adults-United States, 2005-2007. Vaccine 2011; 17;29(22):3850-6. doi: 10.1016/j.vaccine.2011.03.058

[19] Halperin BA, MacDougall D, MacKinnon-Cameron D, Li L, McNeil SA, Langley JM, et al. Universal tetanus, diphtheria, acellular pertussis (Tdap) vaccination of adults: what the Canadian public knows and wants to know. Vaccine 2015; 33:6840-8; PMID:26392011; http://dx.doi.rog/10.1016/j.vaccine.2015.09.012

[20] Skowronski DM, Pielak K, Remple VP, Halperin BA, Patrick DM, Naus M, et al. Adult tetanus, diphtheria and pertussis immunization: knowledge, beliefs, behavior and anticipated uptake. Vaccine. 2004; 23(3): 353-61.

Tables:

Table 1: Demographic characteristics for the study participants

\begin{tabular}{|l|l|l|l|}
\hline Demographic Characteristics & Count & Percentage \\
\hline \multirow{4}{*}{ Gender } & Male & 253 & $67.1 \%$ \\
\cline { 2 - 4 } & Female & 124 & $32.9 \%$ \\
\hline \multirow{5}{*}{ Age } & Less than 18 & 8 & $2.1 \%$ \\
\cline { 2 - 4 } & $18-24$ & 183 & $48.5 \%$ \\
\cline { 2 - 4 } & $25-39$ & 146 & $38.7 \%$ \\
\cline { 2 - 4 } & $40-55$ & 35 & $9.3 \%$ \\
\cline { 2 - 4 } & More than 55 & 5 & $1.3 \%$ \\
\hline \multirow{5}{*}{ Education level } & Less than 5000 & 159 & $42.2 \%$ \\
\cline { 2 - 4 } & $5000-10,000$ & 109 & $28.9 \%$ \\
\cline { 2 - 4 } & $10,000-20,000$ & 77 & $20.4 \%$ \\
\cline { 2 - 4 } & More than 20,000 & 32 & $8.5 \%$ \\
\cline { 2 - 4 } & None & 0 & $0.0 \%$ \\
\cline { 2 - 4 } & Elementary or intermediate & 5 & $1.3 \%$ \\
\cline { 2 - 4 } & Digh school & 121 & $32.1 \%$ \\
\cline { 2 - 4 } & Bachelor & 37 & $9.8 \%$ \\
\cline { 2 - 4 } & Master & 195 & $51.7 \%$ \\
\cline { 2 - 4 } & PhD & 17 & $4.5 \%$ \\
\hline & & 2 & $0.5 \%$ \\
\hline
\end{tabular}

Table 2: Knowledge about tetanus in relation to the demographic characteristics

\begin{tabular}{|c|c|c|c|}
\hline \multirow{2}{*}{$\begin{array}{c}\text { Demographic } \\
\text { Characteristics }\end{array}$} & \multicolumn{2}{c|}{ Have you ever heard of tetanus? } \\
\cline { 2 - 4 } Gender & Male & $34 \%(\mathrm{n}=86)$ & $66 \%(\mathrm{n}=167)$ \\
\cline { 2 - 4 } & Female & $24.2 \%(\mathrm{n}=30)$ & $75.8 \%(\mathrm{n}=94)$ \\
\hline \multirow{4}{*}{$\begin{array}{c}\text { Age } \\
\text { groups }\end{array}$} & $<18$ & $37.5 \%(\mathrm{n}=3)$ & $62.5 \%(\mathrm{n}=5)$ \\
\cline { 2 - 4 } & $18-24$ & $15.8 \%(\mathrm{n}=29)$ & $84.2 \%(\mathrm{n}=154)$ \\
\cline { 2 - 4 } & $25-39$ & $40.4 \%(\mathrm{n}=59)$ & $59.6 \%(87)$ \\
\cline { 2 - 4 } & $40-55$ & $62.9 \%(\mathrm{n}=22)$ & $37.1 \%(\mathrm{n}=13)$ \\
\cline { 2 - 4 } Income & $>55$ & $60 \%(\mathrm{n}=3)$ & $40 \%(\mathrm{n}=2)$ \\
\hline \multirow{4}{*}{ Education } & $<5000$ SAR & $23.3 \%(\mathrm{n}=37)$ & $76.7 \%(\mathrm{n}=122)$ \\
\cline { 2 - 4 } level & $5000-10000$ SAR & $28.4 \%(\mathrm{n}=31)$ & $71.6 \%(\mathrm{n}=78)$ \\
\cline { 2 - 4 } & $10000-20000$ SAR & $44.2 \%(\mathrm{n}=34)$ & $55.8 \%(\mathrm{n}=43)$ \\
\cline { 2 - 4 } & $>20000$ SAR & $43.8 \%(\mathrm{n}=14)$ & $56.2 \%(\mathrm{n}=18)$ \\
\cline { 2 - 4 } & $\begin{array}{c}\text { Elementary or } \\
\text { intermediate }\end{array}$ & $60 \%(\mathrm{n}=3)$ & $40 \%(\mathrm{n}=2)$ \\
\cline { 2 - 4 } & High school & $19 \%(\mathrm{n}=23)$ & $81 \%(\mathrm{n}=98)$ \\
\cline { 2 - 4 } & Diplomat & $27 \%(\mathrm{n}=10)$ & $73 \%(\mathrm{n}=27)$ \\
\cline { 2 - 4 } & Bachelor & $35.4 \%(\mathrm{n}=69)$ & $64.6 \%(\mathrm{n}=126)$ \\
\cline { 2 - 4 } & Master & $52.9 \%(\mathrm{n}=9)$ & $47.1 \%(\mathrm{n}=8)$ \\
\hline & PhD & $100 \%(\mathrm{n}=2)$ & $0 \%(\mathrm{n}=0)$ \\
\hline
\end{tabular}

